\title{
The Importance of Discrimination Analysis to Generalize the Results: The Case of Identification the Connections between the Variables and the Relationship Marketing in Banking Sector in Albania
}

\author{
Dr. Ervin Myftaraj \\ Marketing Department, Business Faculty, "Aleksandër Moisiu" University, Durrës, Albania \\ Email: ervin.myftaraj@yahoo.com \\ Prof. As. Dr. Azeta Tartaraj \\ Marketing Department, Business Faculty, "Aleksandër Moisiu" University, Durrës, Albania \\ Email:azetatartaraj@yahoo.co.uk
}

Doi:10.5901/ajis.2015.v4n2p223

\begin{abstract}
Discrimination analysis shows us whether the respondents answers, that belong to different units, have high variability between them and if the unit with the largest weight ( of which inquiry customers were more numerous in number) dominates the research, allowing us to conclude in the wrong generalizations or generalizations that are accepted. The purpose of this research is to evaluate the importance of discrimination analysis in the process of building the relationship marketing and its connection with the independent explanatory variables. For realization of this research, is used marketing literature and scientific research methods and it has been taken a sample of 346 consumers, who have been answering questions for independent variables and relationship marketing. The selection was made randomly, grouped by demographic distribution according to the region where they live, age, gender, educational level and the sector they work in. The questionnaires were completed in the two major Albanian cities, Tirana and Durres. The paper is based on primary and secondary data for the case of the banking sector in Albania. Conclusions from the Discrimination analysis show that there are differences in the responses of customers for the service among banks. But these changes have the same trend in most of them. Since we have similar reactions for the banking services, from clients of different banks, it allows us to generalize the sample and not take into consideration changes in their response rate.
\end{abstract}

Keywords: Discrimination analysis, relationship marketing, banking sector.

\section{Introduction}

Marketing of reciprocal relations is a discipline that was established in 1980 and aims to establish a long term relationship with customers, especially in terms of personal relationships. This discipline includes a proper understanding of customer needs through comprehension and in accordance with the customer life cycle.

Economist B.Schneider was the father of this discipline, which in 1980 noted: "what a bitter surprise for the market researchers and business people focused on traditional mechanism of promotion, to learn that for a quite ordinary reason, their product is not suitable for the majority of customers.

The first research on this subject was conducted by Christian Grenroos in 1982, the Swedish School of Economics, outlining what the term "interactive marketing "summed up. Since then the term "marketing of interpersonal relations "was defined by Len Berry. The topic was studies a year later by the first generation of marketing theorist, including Professor Theodore Levitt of Harvard University, who tried to study marketing methods through individual transactions. Levitt is also famous for his theory on globalization. He is the man who created this term, as an example of how the American way of life will influence all over the world, enabling the same goods sold in different countries. In fact, direct relationships existed at that time under the concept of contacts between businesses, but in the 90s they were used for the first time in retail sales. Nowadays, there are special companies that provide services only for interactive marketing.

Creating interactive relationships is generally an expensive process and therefore it's not used for all services or goods. According to Len Berry, interactivity can be used in sectors where the customer has the option to choose between replacement products or when the product has a clear cycle of consumption (e.g. seasonal cycle in the garment sector). Other experts have categorized the relationship marketing discipline as "defensive marketing", therefore is aimed that the 
client pays less for what benefits, in exchange for longer loyalty. This contradicts the "marketing offensive", which aims to create new buyers and increase the frequency of customer purchases through better image, prestige and publicity.

To understand the differences in the responses of the respondents, about the quality of services in building marketing relations between commercial banks, where they are clients, it is necessary to conducted analysis of data discrimination. Discriminating analysis shows whether the respondents' answers, belonging to different units (different banks in our case) have high variability between them and whether the bank with greater weight (Inquiry customers of which were more numerous in number ) dominates search, and leads us in the wrong generalizations and the generalizations are accepted. Because we have built constructs for the variables included in the study, which means that we used structural equation modeling SEM, to sum together questions that belong to the same variable, answers "averaged" out with decimals. To avoid this problem, the respondents' answers have been rehabilitated in 4 groups of five degrees that are used for their survey through Likert scale. Group 1 includes responses that vary in the range [1-2], Group 2 includes responses interval] 2-3], Group 3 includes the interval] 3-4] and group 4 includes responses ranging in the interval] 4-5].

Maximizing customer value, means cultivating long-term relationships with them. In the past, manufacturers adjust the offer for every customer; the tailor cared to adopt a customer suit and shoemaker made shoes for every individual. The Industrial Revolution led to the era of massive production. To maximize scale economies, companies began to produce standard goods, before taking requests and left consumers to adapt to what was available. Manufacturers moved from marketing build-for the-demand into the marketing build-for the-stock. Today companies are moving away from wasted expenses of marketing, in a more accurate marketing, designed to build a strong relationship with the customer. Nowadays economies are supported by informational businesses. Information have the advantage to be easy to differentiate, summarized, personalized and to be spread through the network with great speed. Given that companies have improved the quality in gathering information about the individual customer and business partners (authorized dealers' majority, distributors and retailers) and their factors are more flexible in design, they enhance the ability to individualize the market offers, and mass media messages. Mass specification is a company's ability to fulfill the requirements of every customer and to prepare a wholesale of individually designed products, services and communications programs.

\section{Methodology}

The research is descriptive and explanatory regarding the variables and builds a broad picture of the relationship marketing. Data were analyzed through three computer programs SPSS, Mega stat and Statgrafics, using different statistical methods. The study explores these factors using as example the Albanian banking industry.

The paper consists of two parts which are aligned together. The first part is composed by theory, for which we used related literature for arguing the database, the relationship marketing phenomenon and the importance of independent variables. During this part we researched through various publications and studies. All publications taken into consideration are analyzed appropriate conclusions for each were taken, which combined together, give an easily understandable focus on the importance of demographic elements in the collection of data consumers to identify the importance of seven variables in the construction and implementation of relationship marketing in the banking market in Albania.

The second part is built based on a survey with a sample of 346 respondents, who answered 57 questions. The selection of the sample has been made before, by selecting a sample with different age groups (which coincides with the steps of technological development in Albania) and with different educational level, which again goes in proportion to technological development and use the Internet, computer or mobile phone. Also, we tried to have a sample alignment between the two genders. The selection is done randomly and grouped according to age, gender and education. The questionnaires were completed in the two main cities of Albania, Tirana and Durres.

With grouped data we have build an econometric model and we have performed statistical tests, to identify how demographic factors cross with the influencing variables factors in building and implementing marketing in Albania relations and their statistical significances.

\section{Treatment of Literature}

In the current world enterprise carries on its activities in an increasingly competitive situation fierce. Today, customers are faced with a variety of products and services that satisfy their desires. How can be earned and preserved their preference 
in a rentable way? Precisely in this aspect appears the role of relationship marketing. Marketing perspective means the primary task in the enterprise, the identification of a set of exact customer needs and to adapt production to customer delight. To achieve this objective, marketing interacts with management, finance, human resources and other sectors, as it takes into consideration micro and the macro factors. Relationship Marketing is widely defined, but in general, it is considered that includes activities of seduction, maintaining and enhancing customer relationships with an organization. Therefore, it takes into consideration as the marketing strategies of the offensive and defensive, while at the same time, includes elements of customer service. Marketing offensive associated with the profit of new customers, by being oriented towards prospective customers or attract customers to competitors. On the other hand, defensive marketing is concerned about protecting the market share and existing customer base. Consequently, this kind of marketing strategy tends to keep existing customers and generate more business from them. Since the market has become more competitive and have increased threats for the profitability by the comers, various organizations should consider ways to develop relationships with their existing customers in order to protect their market share. To do this, they need to understand how the marketing relationships are developed.

Relationships through Internet marketing refers to the mid-90swhen it started the use of the Internet. Relationship marketing covers a variety of areas, tools and methods, from the proper design of products in electronic form, to the setting of prices and loyalty programs. Using technologies in the relationship marketing has increased the efficiency and effectiveness of customer service. Through internet technologies, the data generated for consumers can be brought directly to applications sales marketing or customer service to be analyzed. Also, I-RM model includes on-line applications that lead to segmentation and adaptation. The success of such efforts can be measured and modified in real time. In a world connected through the Internet, successfully using I-RM model has become the prerequisite for survival and not a competitive advantage. Loyalty programs are an important activity inside a model I-RM. They are programs that identify customers who repeatedly use a product or service. One example of this is that of the airlines, which have frequent travelers programs.

Customer service on the web is one of the primary activities of - RM model, which appears in many forms, the most important are comparative and research skills. With the existence of thousands of online stores, customers find it difficult to find the required products, so these options offer the possibility of search and comparison. Even within an online shop, special site can provide comparison and search features

To understand the model I-RM there are two options: (1) analytical, and (2) behavioral (Kamakura, 2005). Analytical analysis of the model I-RM aims to increase revenue by analyzing customers and data for different purposes (eg, marketing campaigns, product development, pricing, web sites, etc.), while the analysis of the behavior of the model I-RM supports the process and decision management strategies in conducting surveys and experiments. Analysis of behavior has two categories: experimental analysis of behavior and applied behavior analysis. Experimental analysis of behavior includes short answers in a regulated environment, closed laboratory in environmental events, which are controlled by a discriminative stimulus relationship, amplifier and punishment. Within the experimental analysis of behavior, laboratory methods are commonly used to manipulate environmental changes, while respecting the functional relationships between variables related behaviors (DONAHOE and Palmer, 1989; Delprato and Midgley, 1992).

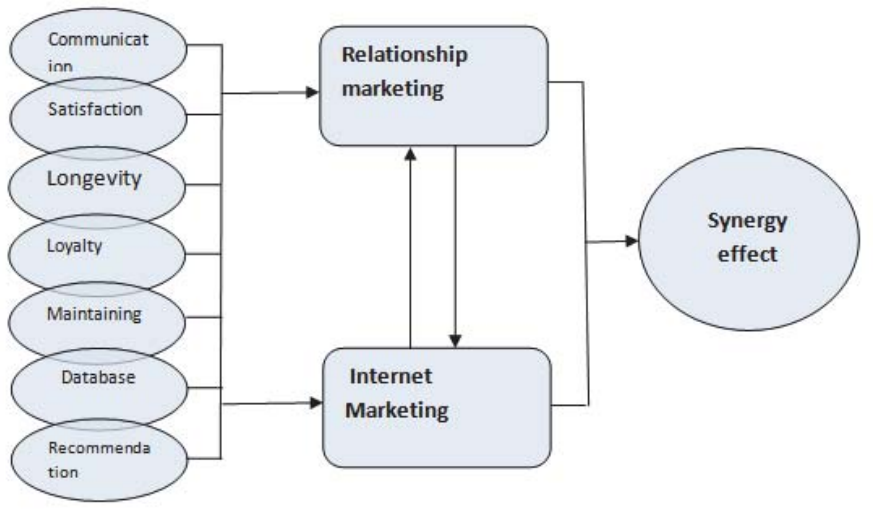

Chart 1. Process model I-RM

Dominant perspective inside relationship marketing research has been to assume that there is a direct and positive 
correlation between relationship marketing variables and elements of internet marketing.

Therefore, the identification of determinants of satisfaction, loyalty, recommendation, database, communication, customer retention and recommendation, is the first priority of the relationship marketing.

This paper treats the relationship between changes of variables, relationship marketing and website. For this reason, it is necessary to examine the factors that affect the model I-RM.

\section{Analysis and Findings}

To understand the differences in the answers of the interviewed, about the quality of services marketing in building relations between commercial banks, where they are clients, it is necessary to carry out the analysis of data discrimination. Discrimination analysis shows whether the respondents' answers, belonging to different units (different banks in our case) have high variability between them and whether the bank with the largest weight (Inquiry customers of which were more numerous in number ) dominates search, and leads us in the wrong generalizations or the generalizations are accepted. Because we have built constructs for the variables included in the study, which means that we used structural equation modeling SEM, to sum together questions that belong to the same variable, answers "averaged" out with decimals. To avoid this problem, the respondents' answers have been rehabilitated in 4 groups of five degrees that are used for their survey through Likert scale. Group 1 includes responses that vary in the range [1-2], Group 2 includes responses interval] 2-3], Group 3 includes the interval] 3-4] and group 4 includes responses ranging in the interval] 4-5]. From the charts below we notice that when we pass from one bank to another, the trend of responses is almost the same for most of the variables.

In the function of this analysis, we developed a procedure designed, built a series of discriminating functions, which help us to forecast banks based on the values of the variables included in the study. To develop this model were used 346 cases (surveys), in order to discriminate among 10 commercial banks. Differences between banks are required for the 7 predictive variables that have been introduced in the model.

Table 1. Discrimination functions for the seven variables

\begin{tabular}{|c|c|c|c|}
\hline Discrimination functions & The function value & The relative proportion & Canonical correlation \\
\hline 1 & 0.854526 & 56.45 & 0.67881 \\
\hline 2 & 0.29586 & 19.54 & 0.47782 \\
\hline 3 & 0.172251 & 11.38 & 0.38333 \\
\hline 4 & 0.114518 & 7.56 & 0.32055 \\
\hline 5 & 0.0445583 & 2.94 & 0.20654 \\
\hline 6 & 0.0170014 & 1.12 & 0.12929 \\
\hline 7 & 0.0151292 & 1.00 & 0.12208 \\
\hline
\end{tabular}

As we can see from the table below, from the seven functions built, 5 discriminating functions with PI-values less than 0.05 are statistically significant at the $95.0 \%$ confidence level.

Table 2. Testing of discriminating functions

\begin{tabular}{|c|c|c|c|c|}
\hline \multirow{2}{*}{ Derived Function } & \multirow{2}{*}{ Wilks Lambda } & & & \\
\cline { 3 - 5 } & & Chi-Square & DF & $P$-Value \\
\hline 1 & 0.295342 & 410.4022 & 63 & 0.0000 \\
\hline 2 & 0.54772 & 202.5701 & 48 & 0.0000 \\
\hline 3 & 0.709769 & 115.3577 & 35 & 0.0000 \\
\hline 4 & 0.832027 & 61.8790 & 24 & 0.0000 \\
\hline 5 & 0.927309 & 25.3952 & 15 & 0.0449 \\
\hline 6 & 0.968628 & 10.7257 & 8 & 0.2177 \\
\hline 7 & 0.985096 & 5.0529 & 3 & 0.1680 \\
\hline
\end{tabular}

To realize the full discriminating analysis, we see the discriminating functions of each bank, for all the variables included in the study. 
Table 3. Discriminating functions of each bank, for each variable

\begin{tabular}{|l|c|c|c|c|c|c|c|c|c|c|}
\hline & RFB & BKT & BC & PCB & TB & ISB & NBG & UB & SG & AB \\
\hline Satisfaction & 0.767323 & 1.65023 & 2.51255 & 3.09917 & 3.77666 & 6.38629 & 4.73699 & 1.96131 & 0.195048 & 0.699875 \\
\hline Longevity & 4.23574 & 4.31502 & 4.48693 & 1.81733 & 3.41722 & 5.02519 & 3.77624 & 4.85348 & 3.5501 & 3.63122 \\
\hline Communication & 1.4901 & 2.0605 & 2.37227 & 1.51644 & 0.526079 & 1.35785 & 2.26332 & 2.74335 & 0.811842 & 0.593799 \\
\hline Database & 2.19018 & 1.26161 & 0.364265 & 1.84359 & 0.567782 & 0.138242 & 2.10536 & 1.66427 & 2.95094 & 3.82473 \\
\hline Recommendation & -0.221826 & -0.918675 & -1.13822 & 0.127433 & 0.144455 & -1.55553 & -2.08459 & -1.30787 & -1.86887 & 0.522687 \\
\hline Maintaining & -0.171699 & 0.0728423 & 1.05242 & 0.044371 & -0.142308 & -0.199073 & -1.07508 & 0.375391 & 0.988696 & -2.49691 \\
\hline Loyalty & 4.11408 & 4.7706 & 3.8728 & 4.41989 & 5.23701 & 4.98432 & 3.65544 & 2.8997 & 6.00916 & 7.43306 \\
\hline CONSTANT & -22.0365 & -23.4151 & -24.8206 & -23.6623 & -24.9469 & -35.1255 & -25.8031 & -24.9419 & -23.4076 & -29.6652 \\
\hline
\end{tabular}

The discrimination function of the first bank (RFB) is=-22,0365 + 0,767323 * Satisfaction+ 4,23574 * Longevity+ 1,4901 * Communication + 2.19018 * Database -0.221826 * Recommendation - Maintaining +0.171699 * 4.11408 * Loyalty

These functions are used to forecast new estimates from surveys to see which bank they belong.

Table 4. The coefficients of functions according to the variables discrimination.

\begin{tabular}{|l|c|c|c|c|c|c|c|}
\hline & 1 & 2 & 3 & 4 & 5 & 6 & 7 \\
\hline Satisfaction & -1.14395 & -0.187767 & -0.205631 & -0.304156 & -0.318475 & 0.0381544 & -0.225584 \\
\hline Longevity & 0.130969 & -0.805816 & -0.699589 & 0.211192 & -0.334995 & -0.0964763 & 0.0375393 \\
\hline Communication & 0.0683357 & -0.546478 & 0.263179 & -0.628405 & 0.567576 & -0.702133 & -0.365203 \\
\hline Database & 0.434362 & 0.758295 & -0.36239 & -0.483082 & -0.0225045 & 0.253572 & 0.964722 \\
\hline Recommendation & 0.177889 & 0.751958 & 0.276397 & 0.565881 & -0.732784 & -0.575636 & -0.258262 \\
\hline Maintaining & -0.028065 & -0.678191 & 0.911651 & 0.120867 & -0.178172 & 0.269938 & 0.385299 \\
\hline Loyalty & -0.112493 & 0.21443 & -0.266612 & 0.616765 & 0.916029 & -0.156284 & 0.319934 \\
\hline
\end{tabular}

The table above shows the coefficient of the functions used to discriminate data among various levels of banks. Of particular interest are the standardized coefficients.

The first function discrimination standardized is $=-1.14395$ * Satisfaction +0.130969 * Life,+ 0683357 * Communication + $0.434362 *$ Database $+0.177889 *$ Recommendation -0.028065 * Maintaining -0.112493 * Loyalty

From the relative size of the coefficients in the above equation, we can determine how independent variables are used to discriminate among groups.

Based on customer survey, in order to see how data constructs are classified according to various banks, we see the table data classification. This table shows the results derived from discriminating functions to classify data among them. The table shows the results among classification functions for each of the 346 observations used to build the model, and for every new observation. For example, row 1 show that the highest level of similarity of data, which have derived from respondents belonging rfb-es, is the bank UB, because in this case we have the highest value, and so on.

Table 5. Classification of Database

\begin{tabular}{|c|c|c|c|c|c|c|c|c|c|c|c|}
\hline Group & Actual & & & & & & & & & & \\
\hline Bank & Nr. & RFB & BKT & BC & PCB & TB & ISB & NBG & UB & SG & AB \\
\hline 1 & 112 & 37 & 12 & 13 & 2 & 0 & 1 & 0 & 17 & 16 & 14 \\
\hline & & $(33.04 \%)$ & $(10.71 \%)$ & $(11.61 \%)$ & $(1.79 \%)$ & $(0.00 \%)$ & $(0.89 \%)$ & $(0.00 \%)$ & $(15.18 \%)$ & $(14.29 \%)$ & $(12.50 \%)$ \\
\hline 2 & 93 & 13 & 25 & 12 & 8 & 5 & 5 & 6 & 13 & 6 & 0 \\
\hline & & $(13.98 \%)$ & $(26.88 \%)$ & $(12.90 \%)$ & $(8.60 \%)$ & $(5.38 \%)$ & $(5.38 \%)$ & $(6.45 \%)$ & $(13.98 \%)$ & $(6.45 \%)$ & $(0.00 \%)$ \\
\hline 3 & 56 & 2 & 6 & 17 & 9 & 2 & 2 & 0 & 12 & 4 & 2 \\
\hline & & $(3.57 \%)$ & $(10.71 \%)$ & $(30.36 \%)$ & $(16.07 \%)$ & $(3.57 \%)$ & $(3.57 \%)$ & $(0.00 \%)$ & $(21.43 \%)$ & $(7.14 \%)$ & $(3.57 \%)$ \\
\hline 4 & 28 & 2 & 1 & 0 & 17 & 4 & 2 & 0 & 1 & 0 & 1 \\
\hline & & $(7.14 \%)$ & $(3.57 \%)$ & $(0.00 \%)$ & $(60.71 \%)$ & $(14.29 \%)$ & $(7.14 \%)$ & $(0.00 \%)$ & $(3.57 \%)$ & $(0.00 \%)$ & $(3.57 \%)$ \\
\hline 5 & 19 & 1 & 0 & 0 & 4 & 6 & 4 & 0 & 1 & 1 & 2 \\
\hline & & $(5.26 \%)$ & $(0.00 \%)$ & $(0.00 \%)$ & $(21.05 \%)$ & $(31.58 \%)$ & $(21.05 \%)$ & $(0.00 \%)$ & $(5.26 \%)$ & $(5.26 \%)$ & $(10.53 \%)$ \\
\hline 6 & 18 & 0 & 1 & 0 & 0 & 0 & 14 & 2 & 1 & 0 & 0 \\
\hline & & $(0.00 \%)$ & $(5.56 \%)$ & $(0.00 \%)$ & $(0.00 \%)$ & $(0.00 \%)$ & $(77.78 \%)$ & $(11.11 \%)$ & $(5.56 \%)$ & $(0.00 \%)$ & $(0.00 \%)$ \\
\hline 7 & 8 & 1 & 0 & 0 & 0 & 0 & 2 & 3 & 1 & 0 & 1 \\
\hline
\end{tabular}




\begin{tabular}{|c|c|c|c|c|c|c|c|c|c|c|c|}
\hline & & $(12.50 \%)$ & $(0.00 \%)$ & $(0.00 \%)$ & $(0.00 \%)$ & $(0.00 \%)$ & $(25.00 \%)$ & $(37.50 \%)$ & $(12.50 \%)$ & $(0.00 \%)$ & $(12.50 \%)$ \\
\hline 8 & 7 & 0 & 1 & 0 & 0 & 0 & 0 & 1 & 4 & 1 & 0 \\
\hline & & $(0.00 \%)$ & $(14.29 \%)$ & $(0.00 \%)$ & $(0.00 \%)$ & $(0.00 \%)$ & $(0.00 \%)$ & $(14.29 \%)$ & $(57.14 \%)$ & $(14.29 \%)$ & $(0.00 \%)$ \\
\hline 9 & 2 & 0 & 0 & 0 & 1 & 0 & 0 & 0 & 0 & 1 & 0 \\
\hline & & $(0.00 \%)$ & $(0.00 \%)$ & $(0.00 \%)$ & $(50.00 \%)$ & $(0.00 \%)$ & $(0.00 \%)$ & $(0.00 \%)$ & $(0.00 \%)$ & $(50.00 \%)$ & $(0.00 \%)$ \\
\hline 10 & 3 & 1 & 0 & 0 & 0 & 0 & 0 & 0 & 0 & 0 & 2 \\
\hline & & $(33.33 \%)$ & $(0.00 \%)$ & $(0.00 \%)$ & $(0.00 \%)$ & $(0.00 \%)$ & $(0.00 \%)$ & $(0.00 \%)$ & $(0.00 \%)$ & $(0.00 \%)$ & $(66.67 \%)$ \\
\hline
\end{tabular}

Among the 346 observations used to build the model, 126 or $36.4162 \%$, are classified properly. This is shown in the graph below:

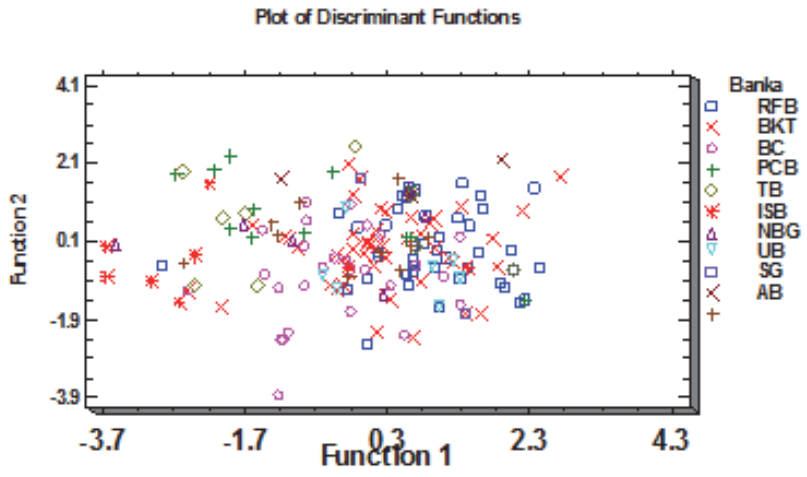

Chart 2. Map data of the discriminating functions

The following table shows the average values of each of the 7 discriminating functions for each of the 10 commercial banks.

In addition to discriminating analysis, presented in the table below are the averages and standard deviations of every variable independently for each bank. Even in this table we notice that the trend of responses is almost the same for all banks, although there are marked differences in percentages.

Table 6. Averages and standard deviations of every independent variable

\begin{tabular}{|l|c|c|c|c|c|c|c|c|c|c|c|}
\hline Bank & RFB & BKT & BC & PCB & TB & ISB & NBG & UB & SG & AB & TOTAL \\
\hline Interviewees & 112 & $\mathbf{9 3}$ & $\mathbf{5 6}$ & $\mathbf{2 8}$ & $\mathbf{1 9}$ & $\mathbf{1 8}$ & $\mathbf{8}$ & $\mathbf{7}$ & $\mathbf{2}$ & $\mathbf{3}$ & $\mathbf{3} 46$ \\
\hline Average & & & & & & & & & & & \\
\hline Satisfaction & 2.58634 & 2.89914 & 3.22107 & 3.7275 & 3.77316 & 4.83167 & 3.91625 & 3.0 & 2.5 & 3.0 & 3.08968 \\
\hline Longevity & 3.53286 & 3.4914 & 3.55375 & 2.60786 & 3.10579 & 3.77778 & 3.0825 & 3.76143 & 3.17 & 3.55667 & 3.43185 \\
\hline Communication & 3.27232 & 3.3871 & 3.51339 & 3.45536 & 2.81579 & 3.33333 & 3.46875 & 3.82143 & 2.75 & 3.33333 & 3.34827 \\
\hline Database & 3.72768 & 3.57527 & 3.58482 & 3.92857 & 3.38158 & 3.91667 & 3.96875 & 4.0 & 3.75 & 4.16667 & 3.68569 \\
\hline Recommendation & 3.5875 & 3.44731 & 3.57143 & 3.96429 & 3.86316 & 3.8 & 2.925 & 3.48571 & 2.8 & 4.06667 & 3.58613 \\
\hline Maintaining & 3.20536 & 3.39785 & 4.07143 & 3.71429 & 3.52632 & 3.83333 & 2.625 & 3.57143 & 4.0 & 2.33333 & 3.47977 \\
\hline Loyalty & 2.63116 & 2.89376 & 2.87571 & 3.00357 & 3.24 & 3.49333 & 2.605 & 2.48857 & 3.07 & 3.43 & 2.85572 \\
\hline Standart deviation & & & & & & & & & & & \\
\hline Satisfaction & 0.709243 & 0.668016 & 0.642803 & 0.92164 & 0.895191 & 0.856238 & 0.937199 & 0.982819 & 0.707107 & 1.0 & 0.928971 \\
\hline Longevity & 0.742935 & 0.670346 & 0.649222 & 0.95044 & 0.693031 & 0.749906 & 1.00436 & 0.598064 & 0.707107 & 0.196299 & 0.771935 \\
\hline Communication & 0.760478 & 0.878886 & 0.978658 & 0.53599 & 0.82007 & 0.874475 & 0.41052 & 1.10599 & 0.353553 & 0.144338 & 0.833899 \\
\hline Database & 0.664032 & 0.819916 & 0.993475 & 0.82736 & 0.859459 & 0.866025 & 0.471273 & 0.989529 & 0.353553 & 0.144338 & 0.808482 \\
\hline Recommendation & 0.855836 & 1.00883 & 0.97042 & 0.923846 & 0.680041 & 0.40584 & 0.925434 & 1.32089 & 1.41421 & 0.46188 & 0.922148 \\
\hline Maintaining & 0.969242 & 1.08487 & 0.931414 & 0.89679 & 1.17229 & 1.04319 & 0.916125 & 0.9759 & 1.41421 & 0.57735 & 1.05275 \\
\hline Loyalty & 0.647377 & 0.551758 & 0.552623 & 0.6554 & 0.553735 & 0.681452 & 0.364221 & 0.75143 & 0.509117 & 0.987269 & 0.641396 \\
\hline
\end{tabular}

\section{Conclusions and Recommendations}

- To understand the differences in the answers of the interviewed, about the quality of services in building marketing relations between commercial banks, where they are clients, it is necessary to carry out the analysis of Database discrimination. 
- Discriminating analysis shows whether the respondents' answers, belonging to different units have high variability between them and whether the unit with the largest weight (Inquiry customers of which were more numerous in number) dominates search, allowing us out in the wrong generalizations or the generalizations are accepted.

- In the present case, in total, descriptive and discriminating analysis we conclude that there are differences in the answers of customers for service between banks. But these changes have the same trend in most of them, although the percentages of responses vary from one bank to another. As we have similar reactions from clients of different banks for banking services, it allows us to generalize the sample, not take into consideration changes in their response rate. In this way, the results of this research will be summarized for the entire banking system. The use of several variables in the model set, explain satisfactorily the reality.

- From the conclusions of discriminating analysis, we give ourselves the right to continue our research, treating the data as a single group. After the identification of the changes of the interviewees in the quality of banks services and after we confirmed the same trend of answers for all the banks, we continue the data processing to identify the connections between variables and relationships marketing, with online marketing and changing these variables under the effect of the internet marketi

\section{References}

Abalo, J., Varela, J., Manzano, V. (2007), "Importance values for Importance-Performance Analysis: A formula for spreading out values derived from preference rankings", Journal of Business Research, Vol. 60, pp. 115-121.

Alberty, S. and Mihalik, B. (1989), "The use of importance-performance analysis as an evaluative technique in adult education", Evaluation Review, Vol. 13, No. 1, pp. 33-44.

Anderson, W. and Mittal, V. (2000), "Strengthening the satisfaction-profit chain", Journal of Service Research, Vol. 3, No. 2, pp. $107-120$. Basu, A. and Muylle, S. (2002), "Online support for commerce processes by web retailers", forthcoming in Decision Support Systems.

Bauer, H. H., Grether, M. and Leach, M. (2002), "Building customer relations over the Internet", Industrial Marketing Management, Vol. 31, No. 2, pp. 155-163.

Dutta, S. and Segev, A. (1999), "Business Transformation on the Internet", European Management Journal, pp. 466-476.

Fullerton, R.A., (1988), "Modern Western Marketing as a Historical Phenomenon: Theory and Illustration", in Newett, T. and Fullerton, R.A. (eds), Historical Perspectives in Marketing, Lexington Books, pp. 73 - 89.

Hoda H. - Myftaraj E., Evaluation of Relationship Marketing, Economy and transition, number 5, December, Tiranë 2009.

Kotler, P.: Paper presented at the trustees meeting of the Marketing Science Institute, November 1990, Boston, referred to in Marketing Science Institute Review (Spring 1991).

Kumar, V. and Reinartz, W.J. „Customer Relationship Management: A Database Approach", John Wiley and Sons, Inc.

Kotler P., 2005, FAQs on marketing, Answered by the Guru of marketing

Kotler, P. and Dubois, B. (2000), Marketing Management, 10th edition, Publi-Union Éditions, Paris.

Lassar Walfried and Chris Manolis(2005), The relationship between consumer innovativeness and online banking adaption, The International Journal of Bank Marketing 23/2 (176-199).

Matzler, K., Bailom, F., Hinterhuber, H., Renzl, B. and Pichler, J. (2004), "The asymmetric relationship between attribute level performance and overall customer satisfaction: a reconsideration of the importance-performance analysis", Industrial Marketing Management, Vol. 33, pp. 271-277.

Myftaraj E.: (2014) "Sinergjia qe krijohet nga nderveprimi i marketingut te marredhenieve me marketingun ne internet. Rasti i industrisë bankare shqiptare". Tezë Disertacioni. "Aleksander Moisiu" University, Durrës, Albania.

Reichheld, F. F. (1994), "Loyalty and the renaissance of marketing", Marketing Management, Vol. 2, No. 4, pp. 10-21.

Sampson, S.E. and Showalter, M.J. (1999), "The performance-importance response function: observations and implications", The Service Industrial Journal, Vol. 19, No. 3, pp. 1-25. 
